\author{
V.M. Sklyarchuk, Z.I. Zakharuk, M.H. Kolisnyk, A.I. Rarenko, \\ O.F. Sklyarchuk, P.M. Fochuk
}

\title{
Effect of Compensation Degree on the Detecting Properties of In-doped $\mathrm{Cd}_{0.9} \mathrm{Zn}_{0.1}$ Te crystals
}

Yuriy Fedkovich' Chernivtsi National University, 2, Kotsiubynskyi Str., Chernivtsi, 58012, Ukraine. e-mail: skliarchuk@chnu.edu.ua

The electrical characteristics of In-doped $\mathrm{Cd}_{0.9} \mathrm{Zn}_{0.1} \mathrm{Te}$ (CZT:In) crystals with concentration of $\mathrm{C}_{\mathrm{o}}=3,5 \cdot 10^{17} \mathrm{~cm}^{-3}$, which are used in $\mathrm{X}$ - and gamma-radiation detectors, were investigated. CZT:In crystals possess a weakly pronounced n-type conductivity and had a resistivity of $(1 \div 2) \times 10^{9} \mathrm{Ohm} \times \mathrm{cm}$ at 293 K. In/CZT:In/In structures with ohmic contacts and Cr/CZT:In/In structures with Schottky barriers were created on their base.

The temperature dependences of the resistivity in investigated material were analyzed and explained. The energy position of the deep level responsible for the material' dark conductivity was found. Due to the study of the temperature dependencies of currents limited by space-charge and of currents of the ohmic section of the volt-ampere characteristics $(I-V C)$, the compensation degree of CZT:In crystals is determined. It was found that Cr/CZT:In/In structures with a Schottky diode, fabricated on crystals with a lower compensation degree, possessed the best detection properties than similar structures fabricated on crystals with a greater compensation degree.

Keywords: $\mathrm{Cd}_{0.9} \mathrm{Zn}_{0.1} \mathrm{Te}: \mathrm{In}$, ohmic contact, CSLCs, compensation degree, Schottky contact.

Work arrived to the editor 27.06.2019; accepted for printing15.09.2019.

\section{Introduction}

$\mathrm{X} /$ gamma-ray radiation detectors based on $\mathrm{Cd}_{0.9} \mathrm{Zn}_{0.1} \mathrm{Te}:$ In $(\mathrm{CZT}: \mathrm{In})$ are practical in industry and medicine, dosimetry and radiology, space research and radio astronomy, and other fields $[1,2]$. To produce these devices, high resistivity rates are required, which are observed in CZT:In crystals [3]. In spite of the great attention given by researchers to the technology and physical properties of CZT solid solution [4-8], the technological problems together with some physical limitations, hold back the wide introduction of such detectors. Hence - the low yield of suitable products, and hence the high cost of appliances.

In this paper, research results of technology, electrophysical parameters of CZT:In, connected with the mechanisms of dark current passage in structures with ohmic contacts and Schottky-contact of Cr/CZT:In/In type are presented. Connection between these parameters and the detection properties of Cr/CZT:In/In structures fabricated on these crystals is considered.

\section{Experiment Methodology}

Recently, the most popular method of doped CdTe and $\mathrm{Cd}_{1-\mathrm{x}} \mathrm{Zn}_{\mathrm{x}}$ Te crystals' growth for the manufacturing of detectors and spectrometers is the method of vertical zone melting through tellurium solution-melt - the method of travelling heater (THM) [4, 9-14]. The advantage of this method is the growth of crystals at a much lower temperature $(1020 \mathrm{~K})$ and additional purification of the material with the tellurium zone.

For the researches presented in this paper, CZT:In crystals were grown by the modified THM (indium concentration in the melt was $\mathrm{C}_{\mathrm{o}}=3.5 \times 10^{17} \mathrm{~cm}^{-3}$ ). In a quartz ampoule, the monolithic CZT:In polycrystal and the weighted tellurium were placed. After creating a vacuum in an ampoule with a material, it was situated in the crystal-growth setup at an angle of $\sim 45^{\circ}$ to the vertical. Crystal growth was achieved by moving the ampoule through a zone heater at a rate of $5 \mathrm{~mm}$ per day with simultaneous rotation it around an axis at a rate of $5 \div 6$ turns per minute for melt mixing to achieve composition homogeneity [15].

To determine the band-gap width, an investigations 


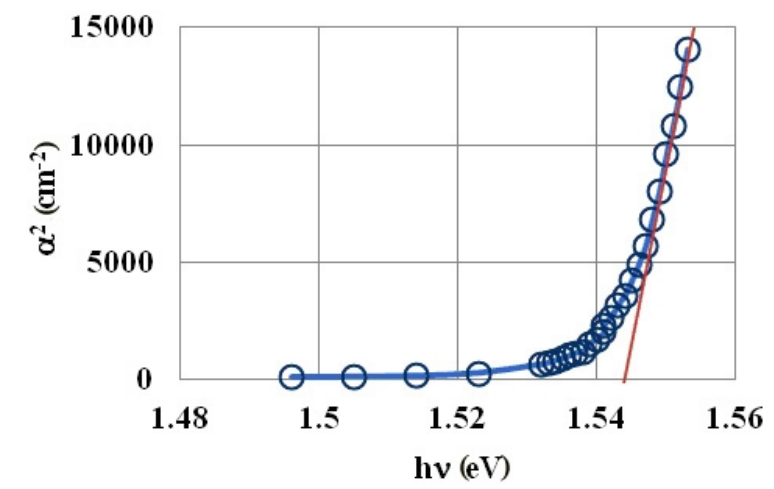

Fig. 1. Dependence of the absorption coefficient $\alpha$ vs. photon energy in n-CZTe:In crystals of 20-25 $\mu \mathrm{m}$ thickness at a temperature of $300 \mathrm{~K}$.

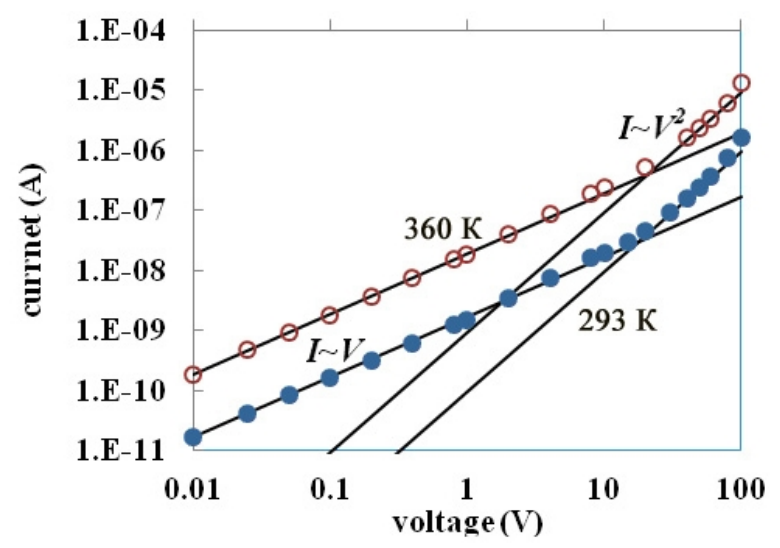

Fig. 2. $I-V C$ of the In/CZTe:In/In structure (crystal of type 1 ) at a temperature of $293 \mathrm{~K}$ (filled circles) and at a temperature of $360 \mathrm{~K}$ (open circles). The solid lines show the $I \sim V$ and $I \sim V^{2}$ areas of $I-V C$.

of the optical absorption edge region of the CZT:In samples were made. To improve the accuracy of optical measurements, the CZT:In wafers were thinned to a thickness of $60 \div 75 \mu \mathrm{m}$ by mechanical grinding and polishing methods. Mechanical treatment leads to the formation of damaged layer on the single crystal surface, which may affect the results of optical measurements [16]. To remove this layer, chemical etching was performed in a bromine-methanol solution. This layer was removed by step-by-step chemical etching in a bromine-methanol solution to a thickness of $20 \div 25 \mu \mathrm{m}$.

The research was carried out on crystalline wafers of the correct form cut from different parts of the ingot. Because of an unhomogeneus distribution of indium on the ingot, they differed in their electrophysical properties and conditionally were called crystals of type 1 (end of the ingot) and crystals of type 2 (middle of the ingot). To determine the homogeneity of zinc distribution in crystals, measurement of the band-gap width of monocrystalline samples in different parts of the ingot was performed. The linear dependence of the $\mathrm{Cd}_{1-\mathrm{x}} \mathrm{Zn}_{\mathrm{x}} \mathrm{Te}$ band-gap width on the zinc content $x$ was used to determine its value [17]:

$$
E_{\mathrm{g}}=E_{\mathrm{go}}+a \cdot x
$$

where $E_{\mathrm{g}}$ is the $\mathrm{Cd}_{1-\mathrm{x}} \mathrm{Zn}_{\mathrm{x}}$ Te band-gap width, $E_{\mathrm{go}}$ is the band-gap width of the cadmium telluride, and $a$ is the proportionality coefficient. $E_{\mathrm{go}}$ is equal to $1.496 \mathrm{eV}$ at $300 \mathrm{~K} . \mathrm{Cd}_{1-\mathrm{x}} \mathrm{Zn}_{\mathrm{x}}$ Te band-gap width was determined from the optical absorption spectra, taking into account the multiple reflections.

Since for the direct-zone semiconductor there is the following relation between absorption coefficient $\alpha$ and band-gap width $E_{g}$ :

$$
\alpha(h v)=\operatorname{const}\left(h v-E_{g}\right)^{1 / 2},
$$

where $h v$ is the photon energy, so $E_{g}$ can be determined from the graph of $a^{2}(h v)$ function, plotted on the basis of experimental data.

The absorption coefficient $\alpha$ was calculated by the formula:

$$
\alpha=\frac{1}{d} \ln \left\{\frac{(1-R)^{2}}{2 T}+\left[\frac{(1-R)^{4}}{4 T^{2}}+R^{2}\right]^{1 / 2}\right\},
$$

where $d$ is the thickness of the sample, $T$ is the optical transmission coefficient, $R$ is the reflection coefficient from the edge of the semiconductor-air boundary, accepted equal to 0.25 in the investigated spectral region [18].

To define $T$, the following formula was used:

$$
T=I / I_{\mathrm{o}} \text {, }
$$

where $I$ is the intensity of light that has passed through the crystal, $I_{o}$ is the total intensity.

To investigate the electro-physical properties, omic contacts were manufactured to the crystalline samples,

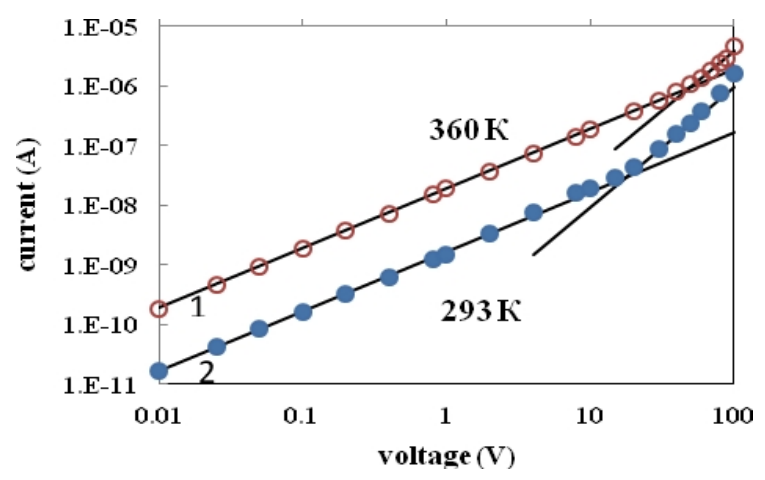

Fig. 3. $I-V C$ of the In/CZT:In/In structures with ohmic contacts (crystal of type 2) at a temperature of $293 \mathrm{~K}$ (filled circles) and at a temperature of $360 \mathrm{~K}$ (empty circles). The solid lines show the $I \sim V$ and $I \sim V^{2}$ areas of $I-V C$.

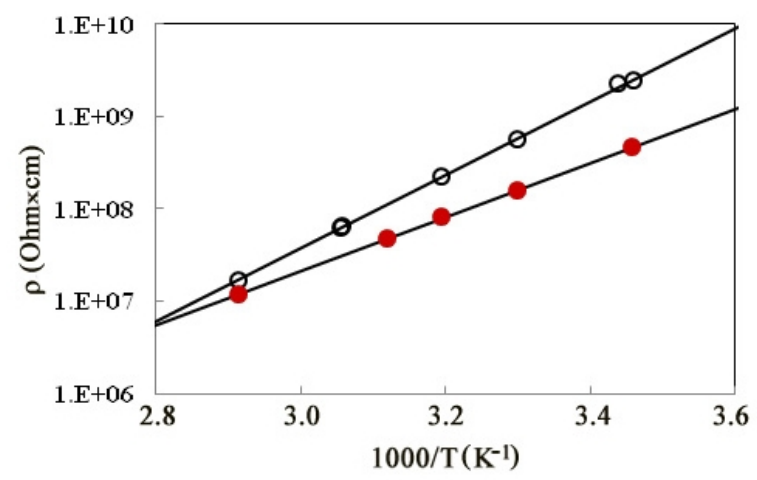

Fig. 4. Temperature dependence of resistivity for CZT:In crystals from different parts of the ingot: empty circles - type 1, filled circles - type 2. 
cut from different parts of the ingot. Investigated samples were $0.8 \div 2.0 \mathrm{~mm}$ thick and had a size of $5 \times 5 \mathrm{~mm}^{2}$. After qualitative mechanical treatment the samples' surface was etched in bromine- methanol solution and washed in methanol. Before applying the metal, the samples' surface was treated in argon plasma at a voltage of $300 \div 350 \mathrm{~V}$ and a current of $35 \div 50 \mathrm{~mA}$ for $10 \div 15$ minutes. Omic contacts to n-type semi-insulating CZT:In crystals were created by thermal spraying of indium in a vacuum. The size of contacts $\left(4 \times 4 \mathrm{~mm}^{2}\right)$ was set by molybdenum masks. In this way, the In/CZT:In/In structure was created.

\section{Results and their discussion} Fig. 1.

The results of optical measurements are shown in

As seen from Fig. 1, a relatively slow change of $\alpha$ in the crystal's transparency region changes by its sharp growth at $h v>1.53 \mathrm{eV}$. In the region of $\alpha>100 \mathrm{~cm}^{-1}$, the observed straight line cuts off a value of $1.543 \mathrm{eV}$ on the axis of photon energies. The band-gap for samples, cut from different parts of the crystal, was within $1.540 \div 1.543 \mathrm{eV}$. Thus, using the known relation (1), it can be argued that zinc content in CZT:In crystals of type 1 and type 2 is practically the same.

Measurements of dark volt-ampere characteristics ( $I$ $V C)$ at different temperatures were performed. $I-V C$ of the In/CZT:In/In structures for crystals of type 1 are shown in Fig. 2. A similar $I-V C$ for a crystal of type 2 is shown in Fig. 3.

$I$-VC for crystals of type 1 and type 2 have the common features, but there are significant differences.

A common in the $I$-VCs behavior for crystals of type I and type 2 is that the ohmic section $I \sim V$ at a voltage $V_{\mathrm{o}}$ changes to a quadratic dependence of the current on a voltage $I \sim V^{2}$. The voltage $V_{\mathrm{o}}$ is determined by the intersection point with the extrapolation of the straight lines $I \sim V$ and $I \sim V^{2}$. Such $I-V C$ behavior is explained within the model of space-charge limited currrents (SCLC) [19]. An important difference between the $I-V C$ is the different temperature dependence of the voltage $V_{\mathrm{o}}$ : for crystals of type 1 this dependence is weak, and for crystals of type 2 it is stronger. It is important to note that the resistivity of the investigated crystals, which was determined from the linear sections of the $I-V C$, was close enough at a temperature of $293 \mathrm{~K}$ : $\sim 2 \cdot 10^{9} \mathrm{Ohm} \times \mathrm{cm}$ for crystals of type 1 and $\sim 10^{9} \mathrm{Ohm} \times \mathrm{cm}$ for crystals of type 2 .

Separately, the temperature dependence of resistivity $\rho(\mathrm{T})$ of the CZT:In crystals cut from different parts of the ingot was investigated. The obtained results are shown in Fig. 4.

From the resistivity temperature dependences, the conductivity activation energies $\Delta E$ for samples from different parts of the ingot were determined, which were equal to $\sim(0.78 \div 0.81) \mathrm{eV}$ for crystals of type 1 and $(0.55 \div 0.6)$ eV for crystals of type 2 .

The investigated n-type CZT:In crystals are

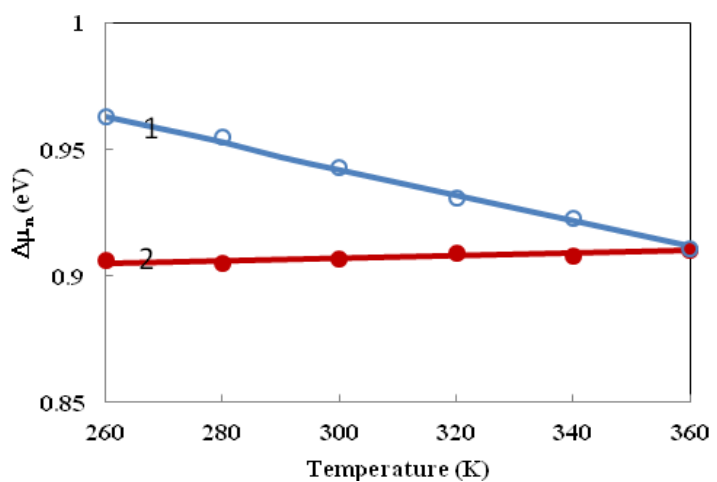

Fig. 5. Dependence of the Fermi-level position on temperature: for crystals of type 1 (filled circles), for crystals of type 2 (open circles). Solid lines show the calculated results.

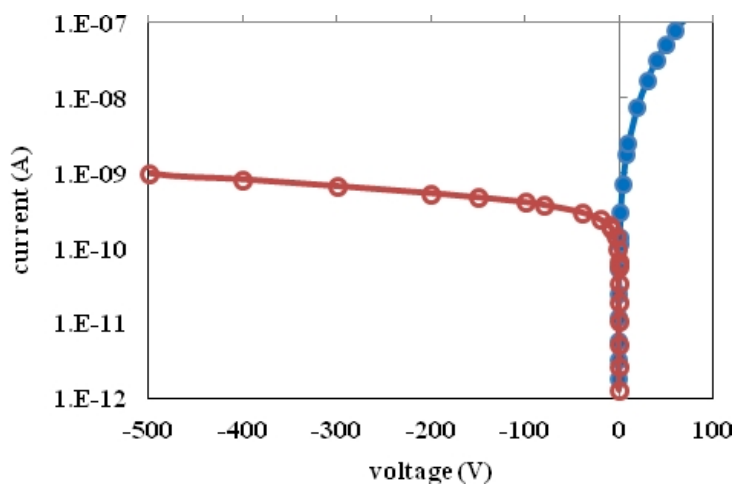

Fig. 6. $I-V C$ of the $\mathrm{Cr} / \mathrm{CZT}: \mathrm{In} / \mathrm{In}$ structure at a temperature of $293 \mathrm{~K}$, filled circles - plus(+) on chromium contact, empty circles - minus (-) on chromium contact.

compensated semiconductors, which have uncontrolled impurities and defects, the concentration of which can be significant. The resistivity temperature dependence of the CZT:In crystal is described by an exponential dependence with the activation energy, $\Delta E$. Analyzing the dark dependence of the CZT:In resistivity on temperature, one can obtain important information about the temperature dependence of the Fermi-level position in the band-gap, as well as about the nature of the impurity, which determines the electrical conductivity [20]. To estimate the energy-level compensation degree that defines the dark conductivity, suppose that the Fermi-level position and the conductivity of the material are determined by a donor with energy, $E_{d}$, and concentration of $N_{d}$, and the concentration of compensating acceptors is denoted as $N_{a}$. For semiconductor with such impurities, the electroneutrality equation looks like:

$$
p+N_{d}^{+}=n+N_{a}^{-},
$$

where $n$ and $p$ are the concentrations of electrons and holes in the conduction band and valence band, $N_{d}^{+}$and $N_{a}{ }_{a}$ are the concentrations of ionized donors and acceptors, respectively.

Then, the electroneutrality equation can be written as follows: 


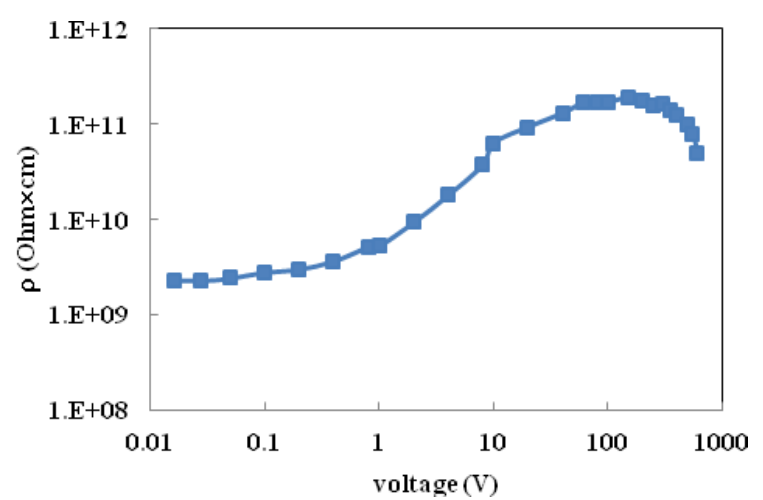

Fig. 7. Dependence of the differential resistance of the $\mathrm{Cr} / \mathrm{CZT}: \mathrm{In} / \mathrm{In}$ structure on the voltage (minus to the chromium contact) at $293 \mathrm{~K}$.

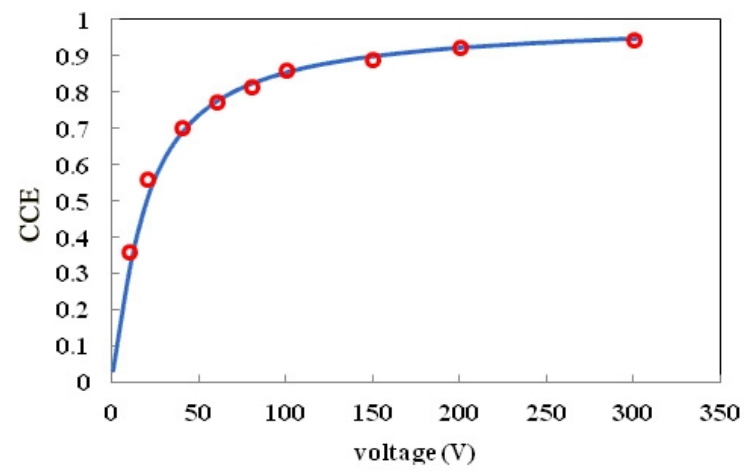

Fig. 8. Photo-response dependence of the $\mathrm{Cr} / \mathrm{CZT}: \mathrm{In} / \mathrm{In}$ structure on the applied voltage (power source 'minus' to the chromium contact) under irradiation by the uncollimated $59.5-\mathrm{keV}{ }^{241} \mathrm{Am}$ gamma-source from the chromium contact (power source 'minus' to the chromium contact) - the empty circles. The solid line is the theoretical curve for CCE $\left((\mu \tau)_{\mathrm{e}}=1.5 \times 10^{-3} \mathrm{~cm}^{2} / \mathrm{V}\right) . \mathrm{T}=293 \mathrm{~K}$.

$$
p+\frac{N_{d}}{1+\exp \left(\frac{\Delta \mu-E_{d}}{k T}\right)}=n+\frac{N_{a}}{1+\exp \left(\frac{E_{a}-\Delta \mu}{k T}\right)},
$$

where

$$
\begin{gathered}
n=\frac{N_{c}}{1+\exp \left(\frac{E_{g}-\Delta \mu}{k T}\right),} \\
p=N_{v} \frac{N_{v}}{1+\exp \left(\frac{\Delta \mu}{k T}\right)},
\end{gathered}
$$

where $\Delta \mu, E_{\mathrm{d}} E_{\mathrm{a}}$ are the depths of the Fermi-level, donor and acceptor levels, respectively, which are which are counted from the edge of the valence band; $N_{\mathrm{c}}=$ $2\left(m_{n} k / 2 \pi \hbar\right)^{3 / 2}$ and $N_{\mathrm{v}}=2\left(m_{p} k / 2 \pi \hbar\right)^{3 / 2}$ are the densities of states in the corresponding bands; the effective masses of electrons $m_{\mathrm{n}}$ and holes $m_{\mathrm{p}}$ in CZT with low zinc content are equal, respectively, $0.11 m_{\mathrm{o}}$ i $0.63 m_{\mathrm{o}}$ [21,22], where $m_{\mathrm{o}}$ is the electron mass in a vacuum. The temperature dependence of the band-gap $E_{\mathrm{g}}(T)$ can be represented as:

$$
E_{\mathrm{g}}(T)=E_{\mathrm{go}}-\gamma \cdot T,
$$

where $E_{\mathrm{go}}=1.68 \mathrm{eV}$, and the temperature coefficient $\gamma=$ $4.0 \times 10^{-4} \mathrm{eV} \mathrm{K}^{-1}$.
On the other side, $\Delta \mu$ value can be determined from the expression for the resistivity:

$$
\rho=\frac{1}{q\left(n \mu_{n}+p \mu_{p}\right)},
$$

where $q$ is the electron charge, $n$ and $p$ are the electron and hole concentrations, $\mu_{n}$ and $\mu_{p}$ are the electrons and holes mobilities, respectively.

$$
\Delta \mu=E_{g}+k T \ln \left(\frac{1 \pm \sqrt{1-4 q^{2} \rho^{2} \mu_{n} \mu_{p} N_{v} N_{c} \exp \left(-\frac{E_{g}}{k T}\right)}}{2 q \rho \mu_{n} N_{c}}\right)
$$

where the sign " \pm " means " $+"$ for the n-type semiconductor and "-" for the p-type semiconductor. The mobility values of electrons $\mu_{\mathrm{n}}$ and holes $\mu_{\mathrm{p}}$ were adopted equal to 700 and $70 \mathrm{~cm}^{2} /(\mathrm{V} \cdot \mathrm{s})$ at $293 \mathrm{~K}$, respectively. Expressions for the mobility temperature dependences are given by Eq. (12-13) according to [23]:

$$
\begin{aligned}
& \mu_{n}=3.54 \times 10^{6} T^{-3 / 2} \mathrm{~cm}^{2} /(\mathrm{V} \cdot \mathrm{s}), \\
& \mu_{p}=3.54 \times 10^{5} T^{-3 / 2} \mathrm{~cm}^{2} /(\mathrm{V} \cdot \mathrm{s}) .
\end{aligned}
$$

The curves obtained by the methods mentioned above are shown in Fig. 5. In equation (10) the data of experimental temperature dependence of the resistivity is used.

Equation (6) is solved numerically relative to $\Delta \mu$. The concentration and depth of the donor and acceptor levels (or $N_{\mathrm{a}} / N_{\mathrm{d}}$ ) are chosen such that the obtained experimental dependences $\Delta \mu(T)$ coincide with the calculation.

It is worth noting that the temperature dependence $\Delta \mu(T)$, found by the experimental temperature dependence $\rho(T)$, can be obtained only at a one combination of $E_{\mathrm{d}}$ and $N_{\mathrm{a}} / N_{\mathrm{d}}$. Coincidence between the calculation and experiment is obtained for $E_{d} \sim 1.0 \mathrm{eV}$ and $N_{\mathrm{a}} / N_{\mathrm{d}}=0.93 \div 0.96$ for a crystal of type 2 , and $E_{\mathrm{d}} \sim$ $0.8 \div 0.82 \mathrm{eV}$ and $N_{\mathrm{a}} / N_{\mathrm{d}}=0.03 \div 0.05$ for a crystal of type 1 . Thus, the dark conductivity in samples from the middle and the end of the ingot is determined by the deep-donor level, which, in one case, is highly compensated, and in other is weakly compensated. The fact that our conclusions are correct is confirmed by the analysis of the SCLC's temperature dependence. If the voltage $V_{\mathrm{o}}$ does independent or is weakly dependent on temperature, then the crystal is weakly compensated, but if it heavily depends on the temperature, then the crystal is highly compensated [24, 25]. According to the research results shown in Figs. 2 and 3, we can clearly conclude that the crystals of type 1 are weakly compensated, and crystals of type 2 are strongly compensated.

Thus, crystals of type 1 and type 2 have a rather close resistivity $\left(\sim 2 \cdot 10^{9} \mathrm{Ohm} \times \mathrm{cm}\right.$ and $\left.\sim 10^{9} \mathrm{Ohm} \times \mathrm{cm}\right)$, but differ strongly by their compensation degree. In terms of the production of ionizing radiation detectors, crystals of both type 1 and type 2 have good electro-physical parameters. Since the crystals differ quite noticeably by the compensation degree, we consider it expedient and important to investigate the connection between this parameter and the detection properties of structures 
fabricated from these crystals. The In/CZT:In/In structures with ohmic contacts proved unsuitable for studying their detection properties, because the $I-V C$ section with a relatively weak current dependence on voltage is limited by the SCLC. The typical value of voltage $V_{\mathrm{o}}$ for crystals with a thickness of $\sim 1 \mathrm{~mm}$ at 293 $\mathrm{K}$ is equal to $\sim 15 \div 25 \mathrm{~V}$. The electric field strength, which corresponds to this voltage, $E \sim 10^{2} \mathrm{~V} / \mathrm{cm}$, is insufficient for the detector's effective operation. Using a rectifying contact instead of an ohmic one allowed us to substantially "extend" the $I-V C$ section with weak current dependence on the voltage. Chromium was used as a metal to fabricate contacts of such type. The indium ohmic contacts were removed by polishing. After chemical treatment in a bromine-methanol solution, one crystal surface was covered by chromium through thermal evaporation in a vacuum, and indium was applied on the opposite side. The surface was treated differently in an argon plasma before applying the metals, in different ways: at a voltage of $300 \div 350 \mathrm{~V}$ and a current of $35 \div 50 \mathrm{~mA}$ before indium deposition, and at a voltage of $500 \div 550 \mathrm{~V}$ and a current of $15 \div 20 \mathrm{~mA}$ before chromium deposition. The size of the contacts was $4 \times 4$ $\mathrm{mm}^{2}$. Thus, Cr/CZT:In/In structures were created. The I$V C s$ of such structures are shown in Fig. 6.

As shown in Fig. 6, the region of current's weak growth on voltage for the $\mathrm{Cr} / \mathrm{CZT}: \mathrm{In} / \mathrm{In}$ structure is substantially larger than that for an In/CZT:In/In with the same sizes of the crystal and the same contact area. In fact, the $I-V C$ straight line of the $\mathrm{Cr} / \mathrm{CZT}: \mathrm{In} / \mathrm{In}$ structure is the $I-V C$ of the $\mathrm{In} / \mathrm{CZT}: \mathrm{In} / \mathrm{In}$ structure. Thus, the $\mathrm{Cr} / \mathrm{CZT}: \mathrm{In} / \mathrm{In}$ structure provides significantly greater electric field strength in a crystal of $\sim 1 \mathrm{~mm}$ thick than does the In/CZT:In/In structure. Quite informative for the $I-V C$ of such structures is the plotting of differential resistance, $d I / d V$, versus voltage $V$ (Fig. 7).

As shown in Fig.7, the differential resistance of the $\mathrm{Cr} / \mathrm{CZT}: \mathrm{In} / \mathrm{In}$ structure at a voltage of $\sim 100 \mathrm{~V}$ is $\sim 2 \cdot 10^{11} \mathrm{Ohm} \times \mathrm{cm}$, which is significantly greater than the crystal's resistivity, which is equal to $\sim 2 \cdot 10^{9} \mathrm{Ohm} \times \mathrm{cm}$ at $293 \mathrm{~K}$. Thus, the formation of the rectifying contact led to a significant increase of the Cr/CZT:In/In structure's tension with a moderate increase of dark current, which did not exceed $1 \mathrm{nA}$ at voltage of $\sim 300 \div 400 \mathrm{~V}$ and temperature of $293 \mathrm{~K}$. We note that the $\mathrm{Cr} / \mathrm{CZT}: \mathrm{In} / \mathrm{In}$ structures, fabricated from crystals of type 1 and type 2, had rather similar I-VCs (Fig. 6 and Fig. 7 show their typical $I-V C s)$.

An important parameter that significantly affects the detector efficiency is the mobility-lifetime product of the charge carriers, i.e., $\mu_{e} \tau_{\mathrm{e}}$ for electrons. It can be determined from the study of the dependence of the photo-response at gamma-irradiation on the electric field strength (or an applied voltage) at room temperature. The product $\mu_{\mathrm{e}} \tau_{\mathrm{e}}$ actually determines the charge collection efficiency $(\mathrm{CCE})$. The $\mu_{e} \tau_{\mathrm{e}}$ value can be obtained from the Hecht equation in the approximation for one type of charge carriers $[26,27]$ :

$$
C C E \approx \frac{\mu_{e} \tau_{e} E}{d}\left[1=\exp \left(\frac{-d}{\mu_{e} \tau_{e} E}\right)\right],
$$

where $d$ is the thickness of the crystal, $E$ is the electric field strength, which depends on the applied voltage. To determine this important parameter, we measured the photo-response dependence of the Cr/CZT:In/In structure on an applied voltage under irradiation by an uncollimated $59.5-\mathrm{keV}^{241} \mathrm{Am}$ gamma-ray source (see Fig. 8).

Since the position of photo-peaks (channels) for gamma-ray spectra are proportional to the $C C E$, the value of $\mu_{e} \tau_{\mathrm{e}}$ can be determined by plotting the photopeaks' positions depending on the applied voltage.

The product $\mu_{e} \tau_{\mathrm{e}}$ determined by such technique is equal to $1.5 \times 10^{-3} \mathrm{~cm}^{2} / \mathrm{V}$ for crystals of type 1 , and $5.0 \times 10^{-3} \mathrm{~cm}^{2} / \mathrm{V}$ for crystals of type 2 . For example, Fig. 8 shows measurements for crystals of type 1 .

Thus, from carried out researches it was found that the product $\mu_{e} \tau_{\mathrm{e}}$ for the weakly compensated crystals of type 1 was approximately three times greater than that for highly compensated crystals of type 2 .

The results obtained by analyzing the $\mathrm{CCE}$
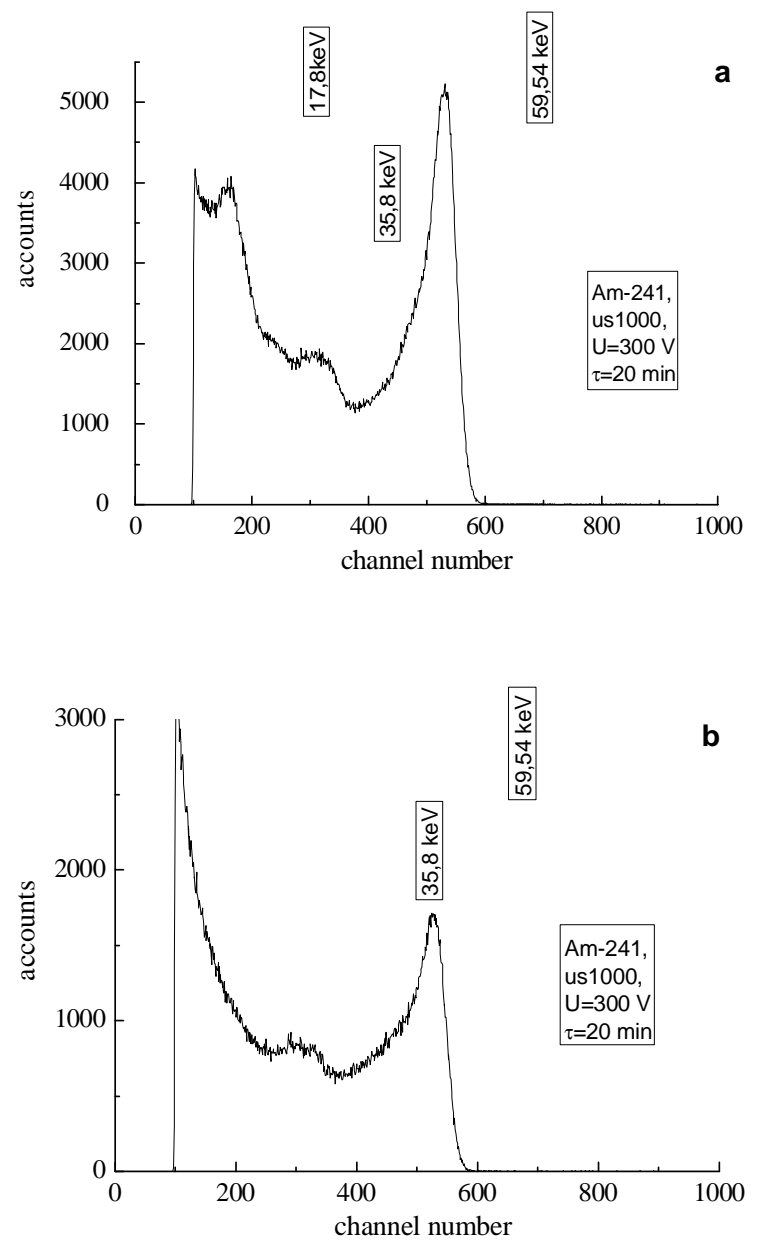

Fig. 9. ${ }^{241} \mathrm{Am}$ emission spectra measured by the detector fabricated from the crystals: (a) - type 1 and (b) - type 2. Voltage $300 \mathrm{~V}$, temperature $300 \mathrm{~K}$. 
measurements are confirmed by measurements of the gamma-ray spectra for samples on the planar $\mathrm{Cr} / \mathrm{CZT}: \mathrm{In} / \mathrm{In}$ structures under irradiation by an uncollimated $59.5-\mathrm{keV}{ }^{241} \mathrm{Am}$ source. Fig. 9 shows the gamma-spectra for $\mathrm{Cr} / \mathrm{CZT}: \mathrm{In} / \mathrm{In}$ structures fabricated on crystals of type 1 and type 2 .

Fig. 9 shows that for crystals of type 1 (from the end of the ingot) the spectrum maximum, which corresponds to the energy of $59.5-\mathrm{keV}$, is narrower. For the best samples, a resolution of $7.05 \% \div 7.56 \%$ was obtained, which corresponds to the full width at half maximum of the spectrum FWHM $=4.2 \div 4.5 \mathrm{keV}$ (see Fig. 9).

\section{Conclusions}

Based on joint studty of the temperature dependence of SCLC and the currents of the $I-V C$ ohmic area of the In-doped $\mathrm{Cd}_{0.9} \mathrm{Zn}_{0.1} \mathrm{Te}$ crystals, the donor nature of the deep level responsible for the dark conductivity was determined. It is shown that the degree of its compensation is bigger the farther it is located from the middle of the band-gap.

It was found that at similar values of the material resistivity, the $\mathrm{Cr} / \mathrm{Cd}_{0.9} \mathrm{Zn}_{0.1} \mathrm{Te}: \mathrm{In} / \mathrm{In}$ structures fabricated on the crystals, in which dark conductivity is caused by a weakly compensated $(3 \% \div 5 \%)$ deep donor level, possessed the better detection properties.

Sklyarchuk $\boldsymbol{V}$. M. - Dr.Sc. (physical and mathematical science), Leading researcher;

Fochuk P.M. - Dr.Sc. (chemical science), Professor, Vice rector for scientific work and international relations; Zakharuk Z.I. - Senior researcher;

Kolisnyk M.H. - Junior researcher;

Rarenko A.I. - Ph.D. (physical and mathematical science), Senior researcher;

Sklyarchuk O.F - Ph.D. (physical and mathematical science).

[1] S.D. Sordo, L. Abbene, E. Caroli, A.M. Mancini, A. Zappettini and P. Ubertini, Review, Sensors 9, 3491 (2009) (https://doi.org/10.3390/s90503491).

[2] A. Brambilla, P. Ouvrier-Buffet, G. Gonon, et al., IEEE Trans. Nucl. Sci. 60, 408 (2013). (doi: 10.1109/TNS.2012.2226910).

[3] Ruihua Nan, Tao Wang, Gang Xu, Man Zhu, Wanqi Jie, J. Cryst. Growth 451, 150 (2016). (https://doi.org/10.1016/j.jcrysgro.2016.07.032).

[4] R. Triboulet, P. Siffert, CdTe and related compounds: physics, defects, technology, hetero- and nanostructures and applications: physics, CdTe-based nanostructures, and semimagnetic semiconductors, defects. European Materials Research Society series. (Oxford: Elsevier, 2010). (https://searchworks.stanford.edu/view/8596311).

[5] A.A. Zakharchenko, A.V. Rybka, V.E. Kutny, A.I. Skrypnyk, M.A. Khazhmuradov, P.M. Fochuk, A.E. Bolotnikov, and R.B. James, Proc. SPIE 8507, Hard X-Ray, Gamma-Ray, and Neutron Detector Physics XIV, 85071I (2012) (https://doi.org/10.1117/12.928567).

[6] K.H. Kim, A.E. Bolotnikov, G.S. Camarda, at al., IEEE. Trans. Nucl. Sci. 59(4), (2012) (doi: 10.1109/TNS.2012.2202917).

[7] L. Davydov, P. Fochuk, A. Zakharchenko, A., Kutny, et al., IEEE Trans. Nucl. Sci. 62(4), 17779 (2015) (https://www.researchgate.net/publication/281058785_Improving_and_Characterizing_CdZnTe_Crystals for Detecting_Gamma-Ray_Radiation).

[8] Pengfei Wang, Ruihua Nan and Zengyun Jian, J. of Semicond. 38(6), 062002 (2017) (https://iopscience.iop.org/article/10.1088/1674-4926/38/6/062002).

[9] M. Amman, J.S. Lee, P.N. Luke, H. Chen, et al., IEEE Trans. Nucl. Sci. 56(3), 795 (2009). (doi: 10.1109/TNS.2008.2010402).

[10] U.N. Roy, S. Weiler, J. Stein, M. Groza, Nuclear Instruments and Methods in Physics Research Section A, Accelerators Spectrometers Detectors and Associated Equipment 652(1), 162 (2011) (doi: 10.1016/j.nima.2011.01.143).

[11] U.N. Roy, A. Burger, R.B. James, J. $\quad$ Cryst. Growth $379, \quad 57 \quad$ (2013). (https://doi.org/10.1016/j.jcrysgro.2012.11.047).

[12] S.M. Koohpayeh, Single crystal growth by the traveling solvent technique: A review. (PROG CRYST GROWTH CH., 2016).

[13] P. Fochuk, Z. Zakharuk, Ye. Nykonyuk, I. Rarenko, M. Kolesnik, A. E. Bolotnikov, G. Yang, and R.B. James, IEEE Trans. Nucl. Sci. 63(3) 1839 (2016) (doi: 10.1109/TNS.2016.2548425).

[14] Boru Zhou, Wanqi Jie, Tao Wang, Liying Yin, J. Cryst. Growth 483 (2017). (doi: 10.1016/j.jcrysgro.2017.12.003).

[15] S.I. Budzulyak, D.V. Korbutyak, L.A. Demchyna, V.M. Yermakov, N.D. Vakhnyak, I.M. Rarenko, Z.I. Zakharuk, M.H. Kolisnyk, P.M. Fochuk, S.H. Dremlyuzhenko, I.Z. Misevych, Sposib vyroshchuvannya monokrystaliv CdTe ta yoho tverdykh rozchyniv CdxZn1-xTe, CdxMn1-xTe, Patent №o 113185, Ukrayina, [in ukr.] Byul. №24, publ. 26.12.2016.

[16] S.G. Dremlyuzhenko, Z.I. Zakharuk, P.M. Fochuk, A.Y. Savchuk, Physics and Chemistry of Solids State 8(4), 748 (2007).

[17] T. Toshifumi T, S. Adachi, H. Nakanishi, K. Ohtsuka, Jpn. Appl. Phys. 32, 3496 (1993). 
[18] Jitendra Kumar Tripathi, S.S. Harilal, S.S. Harilal, Materials Research Express. 1(3), 035904 (2014). (doi: 10.1088/2053-1591/1/3/035904).

[19] M. Lampert and P. Mark, Inzhektsionnyye toki v tverdykh telakh [in rus.] (Mir, Moscow, 1973).

[20] Xu Yadong, Jie Wanqi, Pall Sellin, Tao Wang, et al, J. of Phys. D: Appl. Phys. 42(3), 03505, 082002 (2009) (https://iopscience.iop.org/article/10.1088/1674-4926/30/8/082002).

[21] L.S. Dang, G. Neu, and R. Romestain, Solid State Commun. 44(8), 1187 (1982).

[22] P. Ravindran, Carrier effective mass calculations (Computational Condensed Matter Physics, Spring, 2015) (http://folk.uio.no/ravi/CMT15. http://folk.uio.no/ravi/cutn/ccmp/9-EffectiveMass1.pdf).

[23] B. Segall, M.R. Lorenz, R.E. Halsted, Phys. Rev. 129, 2471 (1963).

[24] G.G. Roberts, F.W. Smidlin, Phys. Rev. 180, 785 (1969).

[25] A.V. Malovichko, S.V. Svechnikov, K.P. Shulga, Ukr. Phiz. J. [in ukr] 20 (2) (1975).

[26] R.H. Nan, W.Q. Jie, G.Q. Zha, J. Nucl. Instrum. Meth. A, 705, 32 (2013) (doi:10.1016/j.nima.2012.12.081).

[27] M. Zanichelli, A. Santi, M. Pavesi \& A. Zappettini, J. Phys. D: J. Appl. Phys. 46(36), 365103 (2013) (https://iopscience.iop.org/article/10.1088/0022-3727/46/36/365103).

\title{
B.М. Склярчук, 3.I. Захарук, М.Г. Колісник, Г.I. Раренко, О.Ф. Склярчук, П.М. Фочук
}

\section{Вплив ступеню компенсації на детектуючі властивості кристалів $\mathrm{Cd}_{0.9} \mathrm{Zn}_{0.1}$ Te, легованих індісм}

\author{
Чернівецький національний університет ім. Юрія Федьковича, м. Чернівиі, 58012, Україна \\ e-mail:skliarchuk@chnu.edu.ua
}

Досліджено електричні характеристики кристалів $\mathrm{Cd}_{0.9} \mathrm{Zn}_{0.1} \mathrm{Te}$, легованих індієм (CZT:In) 3 концентрацією $\mathrm{C}_{0}=3,5 \cdot 10^{17} \mathrm{~cm}^{-3}$, які застосовуються у детекторах X/ $\gamma$-випромінювання. Кристали CZT:In володіли слабко вираженим $n$-типом провідності та мали питомий опір $(1 \div 2) \cdot 10^{9}$ Ом· см при 293 К. На їх основі створено структури $з$ омічними контактами In/CZT:In/In та структури Cr/CZT:In/In 3 діодом Шотткі.

Проаналізовано та пояснено температурні залежності питомого опору в досліджуваному матеріалі. Визначено енергетичне положення глибокого рівня, відповідального за темнову електропровідність матеріалу. На основі досліджень температурних залежностей струмів обмежених просторовим зарядом i струмів омічної ділянки вольт-амперної характеристики, визначено ступінь компенсації кристалів CZT:In. Встановлено, що кращими детектуючими властивостями володіли структури $\mathrm{Cr} / \mathrm{CZT}: \mathrm{In} / \mathrm{In} 3$ діодом Шотткі, виготовлені на кристалах 3 меншим ступенем компенсації, ніж аналогічні структури, виготовлені на кристалах з більшим ступенем компенсації.

Ключові слова: $\mathrm{Cd}_{0.9} \mathrm{Zn}_{0.1} \mathrm{Te}: \mathrm{In}$, омічний контакт, контакт Шотткі, СОП3, ступінь компенсації, детектор $\gamma$-випромінювання. 